\title{
A Local Electricity Market Model for DSO Flexibility Trading
}

\author{
Ricardo Faia ${ }^{1,2}$, Tiago Pinto ${ }^{1}$, Zita Vale ${ }^{2}$, Juan Manuel Corchado ${ }^{3}$ \\ ${ }^{1}$ GECAD Research Group, Polytechnic of Porto (ISEP/IPP), Porto, Portugal \\ $\{$ rfmfa, tcp\}@isep.ipp.pt \\ ${ }^{2}$ Polytechnic of Porto (ISEP/IPP), Porto, Portugal \\ zav@isep.ipp.pt \\ ${ }^{3}$ BISITE Research Centre, University of Salamanca (US), Calle Espejo, 12, 37007 Salamanca, Spain \\ corchado@usal.es
}

\begin{abstract}
The necessity of end-user engagement in power systems have become a reality in recent times. One of the solutions to this engagement is the creation of local energy markets. The distribution systems operators are compelled to investigate and optimize their asset investment cost in reinforcement of grids by introducing smart grid functionalities in order to avoid investments. The congestion management is the one of the most promising strategies to deal with the network issues. This paper presents a local electricity market or flexibility negotiation as a strategy in order to help the distribution system operator in congestion management. The local market is performed considering an asymmetric action model and is coordinated by an aggregator. A case study is presented considering a simulation that uses a low voltage network with 17 buses, which includes 9 consumers and 3 prosumers, all domestic users. Results show that using the proposed market model, the network congestion is avoided by taking advantage from the trading of consumers flexibility.
\end{abstract}

Index Terms-Aggregator, DSO, Flexibility, Local Electricity Market.

\section{INTRODUCTION}

The future of power systems is being redesigned into a system where consumers (end users) are considered to be the central entity in the system. This vision is present in the Strategic Energy Technology (SET) plan of the European Union [1]. This transformation of end-user's roles essentially frames these as entities that have an active contribution in electric power systems. Aggregators enable end-users to be actively involved in the electrical system, namely in the (indirect) participation in electricity markets (wholesale), where they could sell surplus production from local generated renewable energy sources (RES). The widespread of RES allowed the mass appearance of distributed production (solar and wind). The large-scale penetration of distributed, renewable energy has brought new difficulties and challenges to the electrical system, namely due to their variability, which makes production forecasting a difficult task.

This work has received funding from the European Union's Horizon 2020 research and innovation programme under project DOMINOES (grant agreement No 771066) and from FEDER Funds through COMPETE program and from National Funds through FCT under the project UID/EEA/00760/2019
Energy storage systems (ESS) are presented as a solution to mitigate the intermittency of RES [2]. Demand response (DR) is also a solution to deal with the RES problem, since it allows to cut, reduce or shift loads, adapting the consumption to variable generation [3]. DR and ESS are two concepts that apply in real environments enabling flexibility. Flexibility is a mechanism that until now has been used by the transmission system operator (TSO), its function is to adapt the consumption in a certain local to the needs of the electricity network [4]. Recently, with the inclusion of the RESs, the distribution system operators (DSO) have the need to obtain flexibility in the distribution networks. This flexibility has been achieved using an intermediary, the aggregators. Thus, aggregators provide services that allow the DSO to obtain flexibility from the final consumers [5].

This paper presents a different way for DSO to achieve flexibility through a competitive local energy market (LEM). In this LEM, the goal is for the DSO to achieve the required flexibility through a local trading process where market participants are the final consumers. In this sense, when the DSO detects that the need for flexibility in the network, the need is communicated to a local market operator (LMO) (e.g., aggregator). This LMO will encourage the exchange of electricity and flexibility (consumption reduction, increase or shift) between end-consumers. The price of electricity in the local market will be defined between the DSO and the LMO according to the offers placed in the market by the participants.

Results show that this price is more advantageous for endusers than the one that is practiced in the retail market, in both sales and purchase actions. Advantages are also shown for the DSO, which will be interested in this type of actions, because in case of problems in the network (congestion) if the end-users do not receive the electricity service, they will have to be compensated by the DSO.

After this introductory section, section II presents the business model that support the proposed local market model. Section III introduces the proposed methodology, and section IV presents the case study validates the proposed model. Finally, section V presents the conclusions of the work. 


\section{BUSSINESS MODEL}

The presented business model has been developed under the DOMINOES Project [6] and is created based on a three level business model, which is described as follows [7].

First level: Strategic level - The Provider: the aggregator is considered as a service provider. The strategy model: its strategy is deploying flexibility services to the DSO to solve or mitigate congestion management. The flexibility is obtained from its aggregated resources, the consumers, producers and prosumers. All end-users of the network may belong to the aggregators of the aggregator, they will only have to be able to provide the flexibility when the aggregator requires it. The resources model: the aggregator will have in its possession a platform for flexibility transaction that will allow the aggregates to send their proposals. Ensuring additional means to enhance the offered service (e.g., load and generation forecasting, consumption and generation profiling), which can be ensured by internal services or be contracted with external entities. The network model: the aggregator can have external contracts with resources to deploy flexibility in order to overcome the unavailability of end users.

Second level: Customer and Market level - The costumer model: the service is deployed to help the DSO solving congestion situations. It is assumed that the DSO performs a technical validation about grid status, identifying the situations in which flexibility might be procured to avoid congestion issues. The market offer model: Aggregator offer a new service to help the DSO solving congestions situations. Competitors can be producers, consumers and prosumers with direct contracts with the DSO (namely large dimension players). The revenue model: The aggregator acts as an intermediary between the DSO and the aggregated resources. The price per unit of deployed flexibility can result from an asymmetric pool model. For that, the aggregator makes a call auction to its aggregated resources, which will present their bids. The asymmetric pool model will be applied, where all the accepted bids, required to meet the flexibility amount required by the DSO, are paid at the clearing price (equal to the most expensive accepted bid).

Third level: Value Chain level - The delivered model: the deployed flexibility is delivered to the distribution system in reply to the DSO request, materialized as a reduction or an increase of the load. The procurement model: the aggregated resources contribute to the committed load reduction. The Financial model: the Aggregator may obtain the required capital to put the business model in place by bank credit. The sell/provisioned of flexibility must return a sufficient income to cover the payment of such bank credit.

\section{MethodOLOGY}

This section presents the methodology applied in this paper. As already mentioned, the methodology is created to solve problems in the network, is this case the congestion management strategy is used. This strategy can be defined by a service to reduce peak loads in order to avoid thermal overload of system components. Different from a grid reinforcement project, the thermal overload of the system may cause a failure in the short-term horizon so that congestion management requires a swift response from the DSO. Therefore, demand response and flexibility services may find value for the DSO to defer (or in some cases even avoid) grid investments [8].

Fig. 1 presents the simulation process implemented in this work. The process star with the load of the data. The forecast data is performed for the next 24 hours, it is realized considering the historical data. After obtained the forecast values the DSO perform the validation of the network using the power flow analyses. The DSO checks the limits of the network components. If in some period any component is overloaded the DSO determine the quantity of energy for reduce. This information is reported to the aggregator, and the local market can starter. In the Local Market the Aggregator will have the functions of market operator. After the market process is successful, the Aggregator will report the information to the DSO so that it can validate the new dispatch. The DSO will check the network state preforming a new power flow with the update values.

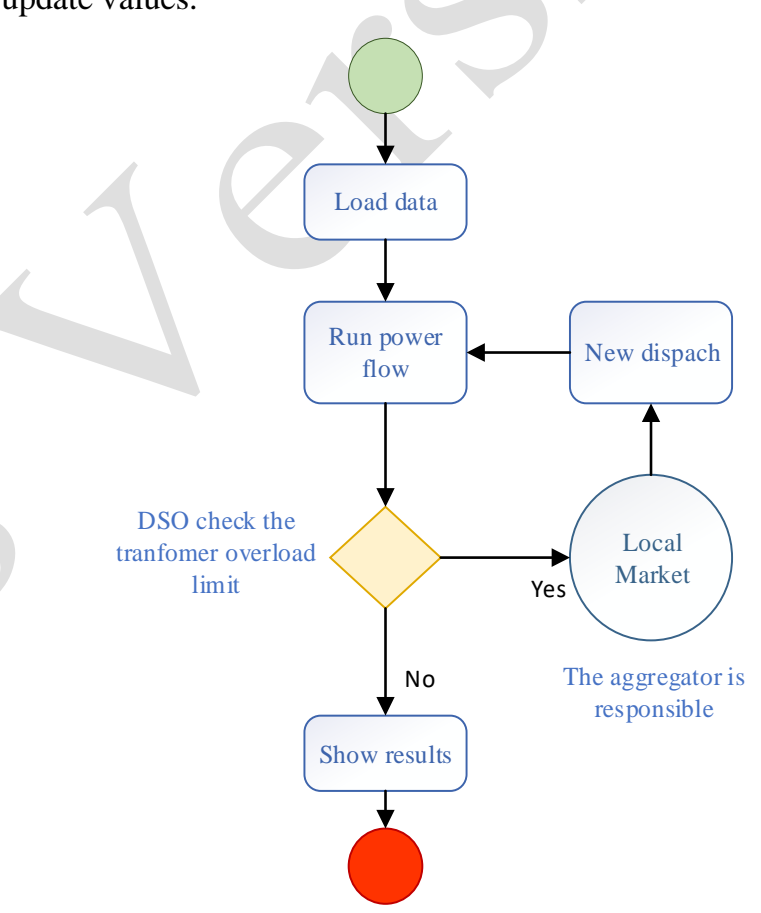

Fig. 1 - Simulation process

The total apparent power at certain point, in this case $x$ in the network at a certain time can give by equation (1).

$$
S_{x, \text { total }}=\sum_{i=1}^{N} S_{i}+\sum_{i=1}^{N} \sum_{k=1}^{N} \text { Slosses }_{i, k}
$$

Where, $S_{x, \text { total }}$ is the total apparent power at point $x, S_{i}$ is the total apparent power in bus $i, i$ and $k$ represent bus in the network, $N$ correspond to the number of the buses, Slosses $s_{i, k}$ correspond to the losses line of bus $i$ to $k$. In equation (2) and (3) represent the apparent power.

$$
\begin{gathered}
S_{i}=P_{i}+j Q_{i} \\
S_{i}=\sum_{k}^{N}\left|V_{i}\right|\left|V_{k}\right|\left(\cos \theta_{i, k}+j \sin \theta_{i, k}\right)\left(G_{i . k}-j B_{i, k}\right)
\end{gathered}
$$


where $P_{i}$ corresponds to the active power of bus $i$ and $Q_{i}$ correspond to the reactive power in bus $i$. The term $\left|V_{i}\right|$ and $\left|V_{k}\right|$ correspond to the absolute value of magnitude voltage in bus $i$ and $k$ respectively, $\theta_{i, k}$ correspond to the difference of bus $i$ and $k$ angles, $G$ correspond to the conductance matrix and $B$ is the susceptance matrix. Equation (4) presents the losses calculation.

$$
\text { Slosses }_{i, k}=I_{i, k}^{2} \times Z_{i, k}
$$

The term $I_{i, k}$ corresponds to the current in line of bus $i$ to $k$ and $Z_{i, k}$ corresponds to the line impedance of bus $i$ to $k$. In equation (5) is present the lines impedance formula.

$$
Z_{i, k}=R_{i, k}+j Q_{i, k}
$$

The term $R_{i, k}$ corresponds to the line resistance of bus $i$ to $k$ and $j Q_{i, k}$ corresponds to the line reactance of bus $i$ to $k$. The line characteristic values are presented in Table 1.

In this study and considering the network present in Fig. 3 if congestion occurs the condition present in equation needs to be verified.

$$
S_{1, \text { total }}>S_{1, \max }
$$

As one can observe in Fig. 3 the transformer is present between bus 1 to 3 and the apparent power in bus 1 correspond to the apparent power requested to the transformer. As equation (6) shows, when $S_{1, \text { total }}$ is greater than $S_{1, \max }$ is considered that the congestion exists.

In case the congestions occurs as mentioned in the business model section, the DSO requests to Aggregator to try to reduce the power of the loads. The Aggregator can active the local market and all end users present in the network can participate. In this case, the bids of power reduction are considered as end users' participation. In this case the bid is created are randomly created. The equitation (7) presented the amount bid creation.

$$
\operatorname{bid}_{i}^{\text {amount }}=\operatorname{rand}(0,1) \times 0.3 \times S_{i}
$$

where $\operatorname{rand}(0,1)$ represents a random number with uniformly distribution between 0 and 1 . Tthe $0.3 \times S_{i}$ means that the power amount for reduce can only reach $30 \%$ of the apparent power of bus $i$. The equation (8) presents the price bid creation.

$$
\operatorname{bid}_{i}^{\text {price }}=\max (0,0.105+0.05 * \text { randn })
$$

where the bid ${ }_{i}^{\text {price }}$ is the maximum between 0 and a random number created with a normally distribution with mean 0.105 and standard deviation of 0.05 . The mean value of 0.105 is chosen considering the price of energy salles for consumers connect to the low voltage network in Portugal [9]. With this rule, it is ensured that the price calculation is always greater than or equal to 0 . In Fig. 2 is presented the normal distribution representation used in this work.

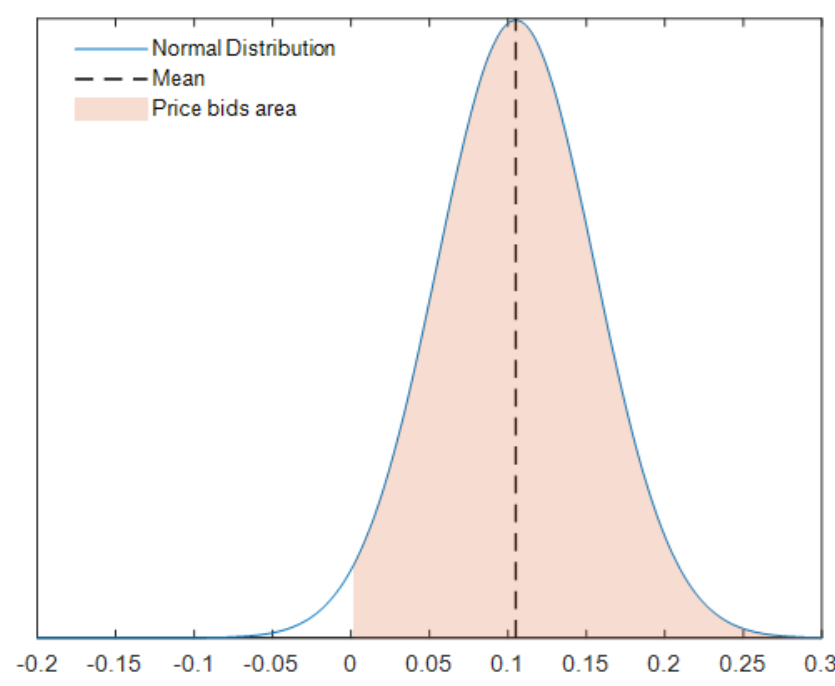

Fig. 2 - Normal distribution

In Fig. 2 the shadow area represents the possible values for price bids. As can see by the Fig. 2 the price there is a high probability that the price value will be close to the average. Is considered that there is a $1.8 \%$ of probability that the price will be 0 , since all values less than 0 go to 0 . The equation (9) present the bid formulation.

$$
\text { bid }_{i}=\left\{\text { bid }_{i}^{\text {amount }} \quad \text { bid }_{i}^{\text {price }}\right\}
$$

where $b_{i d}$ is considered the bid for bus $i$, but only bus with end consumers connect are able for propose bids. The bid is composed by an amount value and a price value.

As already described in the business model section, the implemented local market is created with an asymmetric action model. Considering the characteristics of this model, is necessary that there is a request from the buyer and bids form the sellers. In this case the buyer is the Aggregator and the sellers is the (end-users) consumers. The Aggregator request is given by the equation (10).

$$
S_{\text {requested }}=S_{1, \text { total }}-S_{1, \max }
$$

where the $S_{\text {requested }}$ correspond to the Aggregator request in $\mathrm{kVA}$. In the asymmetric auction model are accepted the bids whose quantity is smaller than the aggregator request. The price is determined by the last bid accepted.

\section{CASE STUDY}

This section is divided into two sub-sections. In the specification sub-section is present the case study and the scenario for which the proposed methodology is implemented. The results sub-section presents the numerical results obtained from the application of the methodology to the case study.

\section{A. Specification}

Fig. 3 shows the low voltage network used in this work to perform the simulations. The network is considered to operate at a $0.4 \mathrm{kV}$ voltage and is fed by a $15 \mathrm{kV}$ medium voltage line. Between buses 1 and 3 is a transformer with a power of $30 \mathrm{kVA}$ and with a transformation ratio of $15 / 0.4 \mathrm{kV}$. The network 
consists of 17 buses, of which 12 buses (6-17) are connected loads of domestic consumers. In the network there is also distributed generation installed that is owned by the consumers. The sum of the contracted power of all the consumers is of 45 $\mathrm{kVA}$, thus the transformer is dimensioned for $66 \%$ of the contracted power.

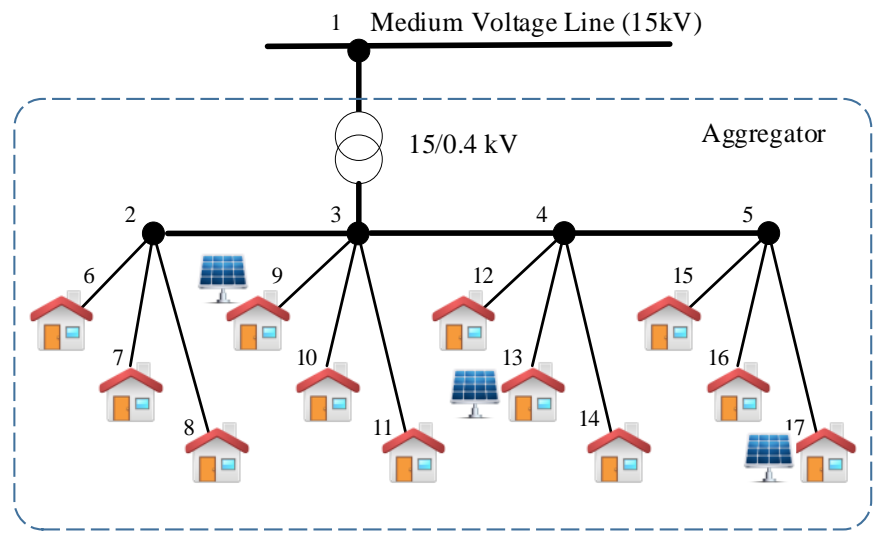

Fig. $3-$ Low voltage network

Table 1 shows the characteristics of the lines that are part of the network shown in the figure Fig. 3. As already indicated, it is assumed that the transformer is located between buses 1 and 3 . Bus lines 2 to 3,3 to 4 and 4 to 5 are lines with 30 meters in length and with the same characteristics. the remaining lines have different lengths, 15 meters ( 2 to 6,3 to 9,4 to 12 and 5 to 15), 20 meters ( 2 to 7,3 to 10,4 to 13 and 5 to 16 ) and 25 meters 2 to 8,3 to 11,4 to 14 and 5 to 17$)$.

Table 1 - Lines characteristics

\begin{tabular}{|l|l|l|l|l|}
\hline $\begin{array}{l}\text { Bus } \\
\text { out }\end{array}$ & $\begin{array}{l}\text { Bus } \\
\text { in }\end{array}$ & Length (m) & $\begin{array}{l}\text { Resistance } \\
(\text { Ohm })\end{array}$ & $\begin{array}{l}\text { Reactance } \\
\text { (Ohm) }\end{array}$ \\
\hline 2 & 3 & 30 & 0.0094 & 0.0103 \\
\hline 3 & 4 & 30 & 0.0094 & 0.0103 \\
\hline 4 & 5 & 30 & 0.0094 & 0.0103 \\
\hline 2 & 6 & 15 & 0.0195 & 0.0031 \\
\hline 2 & 7 & 20 & 0.0260 & 0.0042 \\
\hline 2 & 8 & 25 & 0.0325 & 0.0052 \\
\hline 2 & 9 & 15 & 0.0195 & 0.0031 \\
\hline 3 & 10 & 20 & 0.0260 & 0.0042 \\
\hline 3 & 11 & 25 & 0.0325 & 0.0052 \\
\hline 4 & 12 & 15 & 0.0195 & 0.0031 \\
\hline 4 & 13 & 20 & 0.0260 & 0.0042 \\
\hline 4 & 14 & 25 & 0.0325 & 0.0052 \\
\hline 5 & 15 & 15 & 0.0195 & 0.0031 \\
\hline 5 & 16 & 20 & 0.0260 & 0.0042 \\
\hline 5 & 17 & 25 & 0.0325 & 0.0052 \\
\hline 1 & 3 & Transformer & - & $0.0625^{1}$ \\
\hline
\end{tabular}

In Fig. 4 are present the load profiles aggregated by buses in this case the loads of bus 6,7 and 8 are aggregated in bus 2, the loads of bus 9, 10 and 11 are aggregated in bus 3, the loads of bus 12,13 and 14 are aggregated in bus 4 and the loads of bus 15,16 and 17 are aggregated in bus 5 .
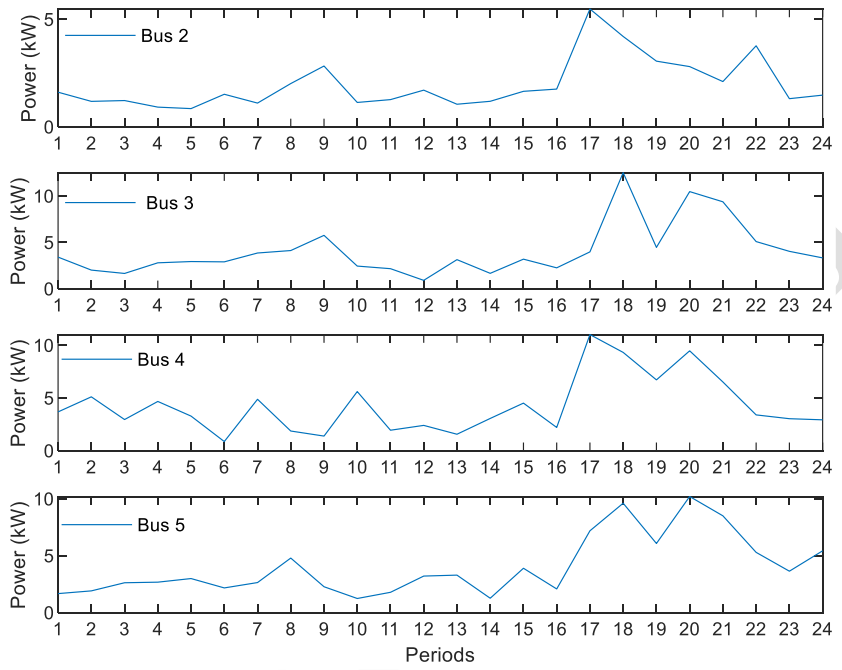

Fig. 4 - Demand profiles per bus

The aggregation of loads is only considered to facilitate the visualization of the data. As one can see by Fig. 4 the profiles are very similar, in the early hours of the morning there is a tendency of consumption as well as in the late afternoon hours and early evening hours. This last period is where the peak of consumption is verified in all points of aggregation.

\section{B. Results}

In this section the results of proposed methodology are presented. Fig. 5 presents the results of the power flow simulation and the production of prosumers. The values present in Fig. 5 represent the total apparent power in bus 1 .

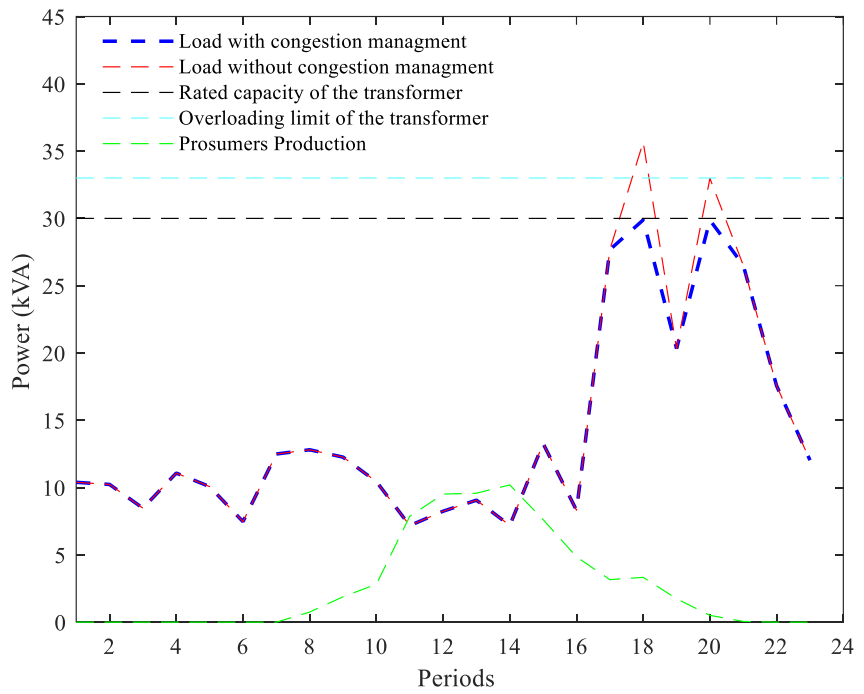

Fig. 5 - Network load and limits

The red line represents the power flow analyses with congestion, and the blue line represents the power flow without congestion. By analyzing the red line of Fig. 5 it is possible conclude that that are two periods when the transformer (bus 1) is overloaded. In the $18^{\text {th }}$ and $20^{\text {th }}$ periods the aggregator needs to activate the local market mechanism to avoid the overload in 
the transformer. Fig. 6 and Fig. 7 are a representation of the asymmetric auction for the periods with congestion.

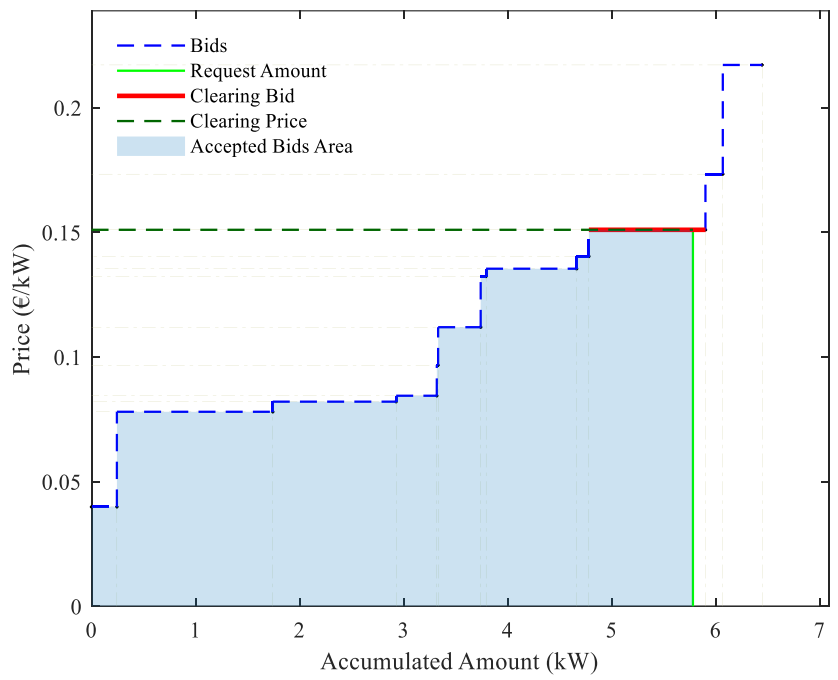

Fig. 6 - Local market results for $18^{\text {th }}$ period

In Fig. 6 is present the asymmetric auction model for $18^{\text {th }}$ period. In Fig. 6 the requested amount is the result of the equation (10), and represent the amount of energy needed for avoid the congestion. This value is equal to $5.78 \mathrm{~kW}$ and considering the result of the market is obtained in the $9^{\text {th }}$ bid. The clearing price is $0.151 € / \mathrm{kW}$, the first 9 bids will be paid at the clearing price. The bids that are out of the accepted bids area are excluded. In the Fig. 7 is present the asymmetric auction model for $20^{\text {th }}$ period.

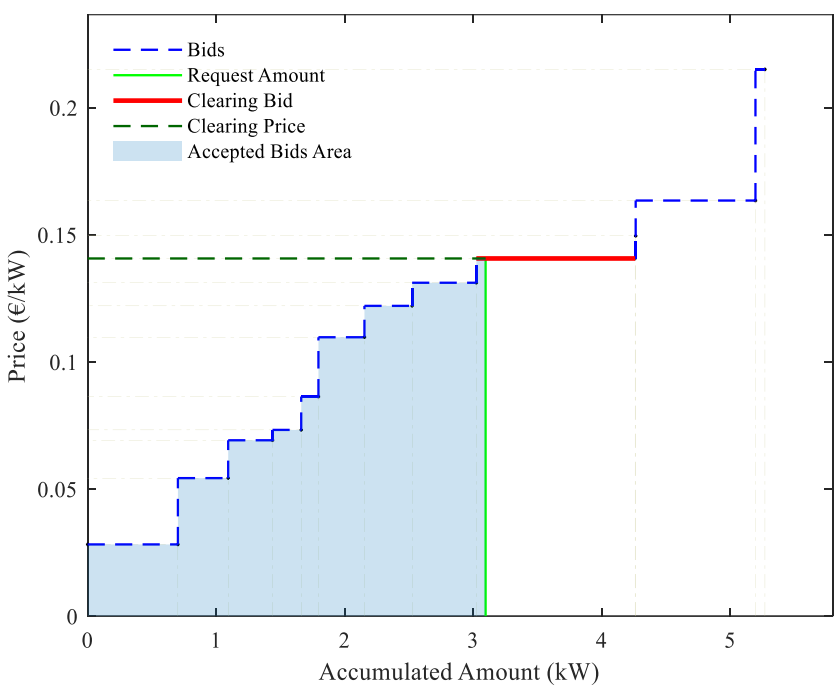

Fig. 7 - Local market results for $20^{\text {th }}$ period

Considering the analysis of Fig. 7 the requested amount is equal to $3.09 \mathrm{~kW}$, also with 9 bids. The clearing price in this period was $0.139 € / \mathrm{kW}$. Considering the results of the market mechanisms the DSO in the $18^{\text {th }}$ will need to pay
$5.78 \mathrm{~kW} \times 0.151 \frac{€}{\mathrm{~kW}}=0.87 €$ for avoid the congestion of the network. In the case of $20^{\text {th }}$ period the DSO for avoid the congestion need to pay $3.09 \mathrm{~kW} \times 0.139 \frac{€}{\mathrm{~kW}}=0.43 €$.

Considering the blue line (load without congestion) in Fig. 5 , there is a $30 \mathrm{kVA}$ of maximum values that corresponds to the maximum capacity of the transformer. If DSO considers an overloading of $10 \%$ for transformer (light blue line), the market mechanism will be applied only one time $\left(18^{\text {th }}\right.$ period $)$.

\section{CONCLUSION}

This paper has proposed a local market model for consumption flexibility trading, as means to complement the DSO congestion management by making use of consumers' active participation.

The proposed methodology shows with the numerical results that it is possible to avoid congestion of the network using a local market strategy. When congestion occurs, the local market for flexibility trading is activated, consumers and prosumers submit their bids, which represent their flexibility amount and associated price, and the asymmetric auction-based market is executed and the needed flexibility amount to avoid congestion is achieved. The bids submitted by the market players are randomized and have no associated intelligence. As future work, players' intelligent behavior will be studied, in order to accommodate strategic bids. It is also intended to test this methodology in a case study with more players and considering the possibility of the players to have energy storage system installed in your facilities.

\section{REFERENCES}

[1] European Union, "The Strategic Energy Technology (SET) Plan," 2017.

[2] R. Hemmati, H. Saboori, and M. A. Jirdehi, "Multistage generation expansion planning incorporating large scale energy storage systems and environmental pollution," Renew. Energy, vol. 97, pp. 636-645, 2016.

[3] R. Faia, P. Faria, Z. Vale, and J. Spinola, "Demand Response Optimization Using Particle Swarm Algorithm Considering Optimum Battery Energy Storage Schedule in a Residential House," Energies, vol. 12, no. 9. 2019.

[4] B. A. Frew, S. Becker, M. J. Dvorak, G. B. Andresen, and M. Z. Jacobson, "Flexibility mechanisms and pathways to a highly renewable US electricity future," Energy, vol. 101, pp. 65-78, 2016.

[5] P. Olivella-Rosell et al., "Local flexibility market design for aggregators providing multiple flexibility services at distribution network level," Energies, vol. 11, no. 4, 2018.

[6] DOMINOES, "Smart Distribution Grid: a Market Driven Approach for the Next Generation of Advanced Operation Models and Services," $2018 . \quad$ [Online]. Available: http://dominoesproject.eu/about/. [Accessed: 20-Sep-2018].

[7] S. Hall and K. Roelich, "Business model innovation in electricity supply markets: The role of complex value in the United Kingdom," Energy Policy, vol. 92, pp. 286-298, 2016.

[8] USEF Foundation, “USEF: The Framework Explained," Usef, 2015.

[9] Ambiente e Transição Energética, "Portaria n. ${ }^{\circ}$ 115/2019," Diário da República n. ${ }^{\circ}$ 74/2019, Série I de 2019-04-15, 2019. . 